\title{
Regras/rupturas do "contrato" amoroso entre adolescentes: o papel do abuso digital
}

\author{
Love "contract" rules/breaches: the role of digital abuse
}

Roberta Matassoli Duran Flach (https://orcid.org/0000-0002-1260-216X) ${ }^{1}$

Suely Ferreira Deslandes (https://orcid.org/0000-0002-7062-3604) ${ }^{1}$

${ }^{1}$ Instituto Nacional de Saúde da Mulher, da Criança e do Adolescente Fernandes Figueira, Fundação Oswaldo Cruz. Av. Rui Barbosa 716, $2^{\circ}$ andar, Flamengo. 22250020 Rio de Janeiro RJ Brasil. matassoli@gmail.com

\begin{abstract}
Digital abuse in intimate relationships is a topic that is still poorly studied in Brazil, and this practice is often naturalized, especially among young people. This article aims to know the meanings attributed by adolescents to the set of rules and agreements, implicit or agreed, that define the contours of a "love contract" and the role of digital abuse in these strategic understandings. Qualitative study conducted with primary oral sources, from four focus groups with adolescents from $\mathrm{pu}$ blic and private schools, of both sexes, aged 15 to 18 years, totaling 26 students. The analysis was based on the perspective of the interpretation of meanings, with thematic bias, anchored in Bauman's theory of liquid love and Giddens' category of confluent love. Trust, individuality and intimacy were values considered essential for the existence of an intimate relationship considered "serious". The "exposure of intimacy" and "monitoring" without permission are acts that can lead to the breakdown of this "love contract". The adolescents showed us that we need to treat digital abuse between partners by reflecting on the rules, values and agreements that define the contours of the "love contract" they establish.
\end{abstract}

Key words Digital abuse, Love, Teen, Affective-sexual
Resumo $O$ abuso digital nos relacionamentos intimos constitui um tema ainda pouco estudado no Brasil, sendo tal prática muitas vezes naturalizada, especialmente entre jovens. O objetivo deste artigo é conhecer os sentidos atribuídos por adolescentes para o conjunto de regras e acordos, implícitos ou pactuados, que definem os contornos de um contrato amoroso e o papel do abuso digital nesses entendimentos estratégicos. Estudo qualitativo realizado com fontes orais primárias, a partir de quatro grupos focais com adolescentes de ambos os sexos, de 15 a 18 anos, de escolas públicas e privadas, totalizando 26 estudantes. A análise se pautou na perspectiva da interpretação de sentidos, com viés temático, ancorado na teoria de amor líquido de Bauman e na categoria de amor confluente de Giddens. Confiança, individualidade e intimidade foram valores considerados essenciais para a vigência de um relacionamento intimo considerado sério. A exposição da intimidade e monitoramento sem permissão são atos que podem levar à ruptura desse contrato amoroso. Os adolescentes nos mostraram que é preciso tratar o abuso digital entre parceiros a partir da reflexão acerca das regras, dos valores e dos acordos que definem os contornos do contrato amoroso que estabelecem.

Palavras-chave Abuso digital, Amor, Adolescentes, Afetivo-sexual 


\section{Introdução}

O abuso digital nos relacionamentos íntimos constitui um tema ainda pouco estudado no Brasil. Uma das primeiras revisões publicadas destaca as agressões diretas e o controle/monitoramento como as práticas mais comuns dessa forma de abuso, sendo muitas vezes naturalizada, especialmente entre adolescentes e jovens ${ }^{1}$. Entre as práticas abusivas mediadas pela tecnologia, destacam-se os inúmeros aplicativos de controle e monitoramento do parceiro íntimo, gratuitamente disponibilizados pelas plataformas digitais Android e iOS. As produções discursivas veiculadas por tais ferramentas se sustentam com argumentos retóricos que remetem à "prova de amor", ao "cuidado" e à "proteção".

Assim, se ao tratar do tema abuso digital nos relacionamentos afetivo-sexuais é importante reconhecer a pluralidade semântica de definições e práticas que dão os contornos desses relacionamentos entre adolescentes ${ }^{3,4}$, entendemos também ser necessária um olhar que coloque em perspectiva a historicidade de seus termos definidores. Afinal, de que amor falamos?

As práticas amorosas têm se transformado ao longo da história e o próprio significado do que seja "amor" não é um conceito unívoco ${ }^{5-8}$. Para empreender tal percurso, tomamos como referenciais a análise feita por Giddens ${ }^{5}$ em sua obra A transformação da intimidade: sexualidade, amor e erotismo nas sociedades modernas e a leitura do consagrado texto de Bauman ${ }^{7}$, Amor líquido: sobre a fragilidade dos laços humanos.

Giddens $^{5}$, ao analisar a constituição contemporânea dos sentidos da intimidade, vai mostrar distintas modelagens da noção de amor que, sem excluir as formas históricas anteriores, instaura uma polissemia e disputa de sentidos. O primeiro modelo, denominado "amor romântico" inaugura, no século XVIII, uma nova forma de relacionamento amoroso, visto não mais como um mero arranjo familiar financeiro, mas como um encontro de almas, uma livre escolha dos parceiros baseada em amor, desejo sexual, casamento, liberdade, autorrealização, maternidade e na ideia de um "amor verdadeiro" e eterno.

Colabora para a consolidação do amor romântico um conjunto de influências que afetaram em particular as mulheres, tais como a criação do lar, a chamada "invenção da maternidade" e a ideia de "mulher respeitável". A centralidade da família até então calcada na autoridade patriarcal volta-se para a afeição maternal. "A idealização da mãe foi parte integrante da moderna construção da maternidade, e sem dúvida alimentou diretamente alguns valores propagados sobre o amor romântico"s.

Após o século XIX, a separação entre lar e trabalho e a redução do número de filhos passam a ser demandadas das mulheres em função de sua inserção no mercado de trabalho, afetando o próprio poder patriarcal exercido dentro do espaço do lar. Por ideologia patriarcal, entendese a manutenção e reprodução de uma estrutura de poder desigual entre os gêneros, cuja supremacia é exercida pelo homem sobre a mulher, subordinando-a, e, por extensão, as identidades associadas ao feminino e aquelas que borram as fronteiras pré-definidas de gênero'. Assim, o patriarcado funciona como uma máquina de "força institucional que se capilariza nas relações sociais, impregnando práticas sociais, instituições sociais e modos de ser e de pensar, ganhando assim, naturalidade pela legitimidade que lhe é conferida".

A partir da segunda metade do século XX, com a crescente emancipação e autonomia sexual feminina, os ideais de amor romântico começaram a perder espaço para a expansão de outras modelagens, como a do "amor confluente". "O amor confluente é um amor ativo, contingente, $\mathrm{e}$ por isso entra em choque com as categorias 'para sempre' e 'único' da ideia de amor romântico [...]. Quanto mais o amor confluente consolida-se em uma possibilidade real, mais se afasta da busca da 'pessoa especial' e o que mais conta é o 'relacionamento especial"'s (p.72).

A busca pelo "relacionamento especial" surge do amor confluente como um ideal, numa sociedade onde todos teriam a oportunidade de se tornar sexualmente realizados, presumindo a igualdade na doação, no recebimento emocional e no conhecimento das peculiaridades do outro, numa ordem amorosa negociada. Tais conceitos, portanto, divergem diretamente da ideia de amor romântico que sujeita a mulher ao âmbito doméstico, subordina-a ao homem, confina sua sexualidade ao casamento e ao símbolo de "mulher respeitável"s.

A partir dos anos 2000, a Internet e suas inovações tecnológicas digitais ampliaram ainda mais as possibilidades de conexão e hiperconexão, propiciando a ruptura de barreiras geográficas e mesmo presenciais. Conhecida como segunda geração da World Wide Web, a Web 2.0 amplia as possibilidades de trocas de informações entre as pessoas, incluindo a colaboração em sites e serviços digitais, transformando o ambiente on -line em campo interacional dinâmico, alterando 
mundialmente a maneira como se conformam as relações íntimas e interpessoais cotidianas. As redes sociais digitais surgem dentro desse contexto e passam a funcionar como mediadores estratégicos das relações sociais, inclusive afetivosexuais. Tais alterações transformaram o "estar conectado" em "ser conectado", modificando os comportamentos e tornando impossível separar na cultura da conectividade, a vida on-line, da off-line ${ }^{10}$.

Nessa cultura, a intenção de dar-se a conhecer é uma constante, com o estabelecimento de laços fracos, que podem se desfazer e se refazer a qualquer momento $^{10}$. Resgatando o sentido dos vínculos efêmeros na ordem amorosa, Bauman ${ }^{7}$ vai retratar os impactos de uma cultura capitalista de consumo na ordem dos afetos amoroso-sexuais. O imediatismo, o consumismo e o hedonismo serão valores determinantes na produção de vínculos rasos, visando o prazer passageiro, sem contrapartidas.

Assim, o conjunto de experiências a que se refere pela palavra "amor" se expande. Os relacionamentos afetivo-sexuais contemporâneos estarão fortemente vinculados à experimentação da sexualidade. "Noites avulsas de sexo são referidas pelo codinome de 'fazer amor"'7. A busca incessante e abundante por experiências amorosas, as mais diversas, ocupam cada vez mais o espaço do amor romântico de outrora.

Na sociedade atual, declarar amor eterno a alguém é visto como um decreto de aprisionamento. Para Bauman ${ }^{7}$, vivemos o modelo do "amor líquido”, uma relação instantânea e disponível. "Nada de apaixonar-se... Nada daquela súbita torrente de emoções que nos deixa sem fôlego e com o coração aos pulos. Nem as emoções que chamamos de 'amor' nem aquelas que sobriamente descrevemos como 'desejo'” (p. 37) 7 .

No modelo designado como "amor líquido", as relações íntimas se dão por conveniência, por impulso, e devem ser consumidas instantaneamente, de uma única vez, e ser descartável. A ordem do dia é satisfazer os desejos e experimentar, sem preconceitos, demarcando assim novas gramáticas sexuais-morais. O relacionamento se mantém apenas enquanto ambas as partes estiverem proporcionando prazer e satisfação suficientes à sua manutenção ${ }^{7}$.

Nesse cenário em que as relações se tornaram mais fluídas, frágeis e com redução de vínculos duradouros, os adolescentes também são convocados a reatualizar os sentidos de suas práticas amorosas: "[...] o adolescente se vê impelido a instituir o modo típico de relacionamento deste tempo: relações abreviadas, voltadas para a satisfação de necessidades e desejos imediatos, sem compromissos que ultrapassem o momento da relação" (p. 70) $)^{11}$.

Dentro desse contexto relacional mais íntimo, marcado pelas disputas entre os distintos modelos de amor, há tensões constantes que visam estabelecer limites, sejam estes (in)formalmente demarcados, numa espécie de "contrato amoroso", que estabelece o que é ou não permitido, aceito, negociado ou perdoado. "Dentre as normas acordadas pelo casal, existem aquelas que não podem ser flexibilizadas [...], a mentira não é aceita, pois leva a quebra de confiança que é indispensável na relação" (p. 521) ${ }^{12}$.

Os relacionamentos, agora cada vez mais mediados por tecnologias digitais, precisam também incorporar em seus "contratos amorosos" um conjunto de regras de consentimento mútuo sobre os usos dessas tecnologias, delimitando as fronteiras do que passa a ser visto como "abusivo".

Os abusos digitais no contexto dos relacionamentos afetivo-sexuais são definidos internacionalmente como "cyber dating abuse (CDA)". Segundo Flach e Deslandes", por ser um fenômeno emergente, ainda não suficientemente definido na literatura científica, o CDA pode ser caracterizado como uma nova expressão da violência entre parceiros íntimos (VPI), "com características específicas e elementos diferenciados da violência ocorrida no namoro face a face e no cyberbullying, perpetrado por meio do uso da Internet e de tecnologias digitais que não têm barreiras geográficas ou temporais para sua expressão, com a intenção de causar danos ao(à) parceiro(a), e com importantes consequências à saúde mental de suas vítimas"1.

Os tipos de abuso digitais mais comuns são: 1) agressão direta; 2) controle/monitoramento; 3) "sexting" como pornografia de vingança; e 4) "sextorsão".

$\mathrm{Na}$ agressão direta são realizadas ameaças, insultos, disseminação de informações privadas, incluindo fotos e vídeos pessoais, roubo de identidade por meio da criação de perfis falsos em redes sociais, rastreamento da última conexão, uso de senha pessoal do(a) (ex)parceiro(a) sem o consentimento para verificar e-mail, contatos telefônicos, mensagens de texto e de rede social, ou até mesmo para monitorar a localização via GPS, com a intenção de o(a) humilhar e emba$\operatorname{raçar}^{1,13-15}$.

O controle/monitoramento é feito via aplicativos gratuitos disponibilizados nos sistemas Android e iPhone que possibilitam o controle 
remoto do aparelho de outra pessoa, sem o conhecimento e consentimento da mesma. Entre as diversas funções disponibilizadas por esses aplicativos, estão: o uso de "cercas eletrônicas", controle de localização, escuta de ligações telefônicas, acesso a mensagens de texto, às redes sociais, ao e-mail, à galeria de imagens e vídeos, clonagem do WhatsApp, para citar apenas algumas. A promessa de segurança e manutenção de uma "paz de espírito" são dispositivos discursivos que naturalizam o uso de aplicativos de controle e monitoramento do(a) parceiro(a). Essas práticas enraizadas no cotidiano dos relacionamentos afetivo-sexuais reiteram antigas violências e retiram $\operatorname{dos}$ (as) parceiros(as) o direito à liberdade $\mathrm{e}$ a inviolabilidade de suas informações ${ }^{2}$.

O sexting é o que passou a ser chamado de pornografia de vingança ${ }^{14,16,17}$, trata-se da ameaça de divulgar nudes e vídeos íntimos feitos e trocados voluntariamente durante a vigência do relacionamento íntimo, obrigando uma pessoa a fazer algo que ela não quer. Por ser um círculo vicioso de abuso, pode durar muito tempo e gerar danos graves à saúde, podendo levar à depressão e até ao suicídio. Vale pontuar os riscos moralizantes desse deslocamento semântico de uma prática abusiva envolvendo a exposição do corpo nu para a noção de pornografia (associado ao prazer sexual).

A sextorsão se refere à ameaça de expor fotos e vídeos íntimos de alguém, caso essa pessoa não aceite pagar um valor exigido (extorsão). Por ser um fenômeno ainda pouco estudado, especialmente no Brasil, há poucos dados a respeito. Contudo, a SaferNet Brasil - organização civil com foco na promoção e defesa dos direitos humanos na Internet no Brasil - recebeu, só no primeiro semestre de 2018, 332 pessoas buscando ajuda porque sofreram ameaça ou tiveram seus nudes compartilhados sem autorização ${ }^{18}$.

No repertório traçado pela literatura para descrever esse fenômeno, figura como tópos discursivo obrigatório reconhecer as consequências para a saúde daqueles que sofrem tal abuso. Assim são identificados os danos a identidade, autoestima, integridade e privacidade, deixando marcas psíquicas (ansiedade, depressão, distúrbio do sono, ideação e tentativa de suicídio) cujas extensões ainda são pouco conhecidas ${ }^{1,13,15,19-23}$.

Essas consequências nos alertam para a importância do olhar diferenciado dos profissionais de saúde para a abordagem desses temas junto aos adolescentes e para a sua pronta identificação nos serviços de saúde, em face à vulnerabilidade desse público para sofrer e praticar tais formas de abuso.
Neste estudo tomamos por base a definição de violência nas relações afetivo-sexuais adotada pela Convenção de Belém do Pará $(1994)^{24}$, entendendo esta como: qualquer ação ou ato, seja de natureza física, psicológica, verbal, moral ou mesmo de natureza simbólica, que cause morte, dano ou sofrimento ao outro. Todavia, a ampliamos ao considerar a definição êmica proposta por Nascimento e Cordeiro ${ }^{12}$, segundo a qual os jovens consideram violência nas relações íntimas "qualquer ato que invada o limite do outro [...], qualquer transgressão ao espaço do outro, entendendo-se esse espaço não só em seu aspecto físico, corpóreo, mas como aquele inerente a sua subjetividade, seus desejos e ideais" (p. 523) ${ }^{12}$.

Assim, o objetivo deste artigo é conhecer os sentidos atribuídos por adolescentes para o conjunto de regras e acordos, implícitos ou pactuados, que definem os contornos de um "contrato amoroso" e o papel do abuso digital nesses entendimentos estratégicos. Nossa questão de investigação foi assim desenhada: quais os sentidos e experiências relatados pelos adolescentes sobre o abuso digital e como afetam seus "contratos amorosos"?

\section{Metodologia}

O presente artigo constitui um estudo de natureza qualitativa, com fontes orais primárias cujo campo do estudo foram duas escolas cariocas (uma delas particular, na zona sul, e outra pública federal, politécnica, no subúrbio). A escolha de escolas com perfis diferentes permitiria investigar se haveria diferenças significativas entre os sentidos atribuídos à temática nos diferentes extratos sociais. Contudo, os resultados não sustentaram distinções nas representações nem nas vivências relatadas.

Os estudantes da escola federal foram aprovados por concurso público, sendo provenientes de famílias de extratos de renda baixos e médios. Já os estudantes da escola particular residiam na zona sul do Rio de Janeiro, sendo a maioria das camadas médias.

A opção por tomar os adolescentes como os sujeitos do estudo se deu em função de diversas pesquisas nacionais e internacionais apontarem tal segmento como o de maior vulnerabilidade para a ocorrência de violência nas relações afetivo-sexuais ${ }^{25-29}$.

Foram realizados quatro grupos focais com adolescentes de ambos os sexos, com idades entre 15 e 18 anos, buscando compor uma amostra he- 
terogênea quanto à etnia/raça e extratos sociais. Participaram um total de 26 estudantes. Das 22 moças, três tinham 15 anos, 15 estavam com 16 anos e quatro tinham 17. Dos quatro rapazes, dois estavam com 15 anos e dois tinham 17.

Oriunda da psicologia e com aplicação na pesquisa social, adotamos a técnica projetiva ${ }^{30}$, que constitui a oferta de fotos, histórias, filmes ou outros materiais que permitam ao grupo, a partir daquele estímulo inicial, invocar por associação as suas próprias vivências. Utilizamos dois casos fictícios sobre abuso digital nos relacionamentos íntimos para mobilizar os debates dos grupos focais, que foram gravados em MP3 e posteriormente transcritos.

No primeiro caso, buscou-se debater o controle/monitoramento por meio de aplicativo que duplica no celular de quem está monitorando as mensagens recebidas pelo parceiro íntimo, sem o seu conhecimento e consentimento. $\mathrm{O}$ caso retrata dois jovens de 17 anos, heterossexuais, que namoram há seis meses. Contudo, a moça passa a desconfiar que o namorado está se interessando por outra garota e baixa um aplicativo que clona, no celular dela, as mensagens de WhatsApp do namorado sem ele saber, passando a ter acesso a todas as mensagens dele.

No segundo caso, buscou-se refletir sobre a "pornografia de vingança", materializada na divulgação de vídeo, foto ou arquivo íntimo na Internet sem a permissão de um dos parceiros. Nesse caso, a situação retratava a história de três jovens (uma moça de 15 anos e dois rapazes de 16 anos). Na primeira parte do enredo, a menina e um dos rapazes trocam nudes pelo WhatsApp, num jogo de sedução, mas sem estar num relacionamento sério. Na segunda parte do enredo, a jovem conhece outro rapaz com quem começa a namorar e então diz ao primeiro rapaz que não trocaria mais nudes com ele. Então o jovem "rejeitado" resolve enviar em um grupo de WhatsApp de amigos em comum aos dois, sem o consentimento dela, os vídeos e as fotos íntimas que a jovem havia enviado para ele.

A duração dos grupos variou entre 50 e 58 minutos. Foram conduzidos pela primeira autora e por um pesquisador auxiliar na função de relator. Foram compostos grupos só por rapazes e outros somente com as moças, com no máximo dez participantes.

Para fins de proteção dos sujeitos e melhor categorização e análise do material coletado, foram adotadas as seguintes siglas, seguidas da numeração ordinal: EPuMa (Escola Pública-Meninas); EPuMo (Escola Pública-Meninos); EPaMa
(Escola Particular-Meninas). Na escola particular, não houve quantitativo mínimo necessário de meninos interessados em participar do grupo focal.

A partir de sucessivas leituras temáticas ${ }^{31}$, os depoimentos foram agrupados em três grandes blocos, sendo identificados todos os subtemas de cada unidade. A análise foi conduzida pela proposta de "interpretação de sentidos" de Gomes e colaboradores ${ }^{32}$, integrando redes de significantes (palavras, ações, expressões) a sentidos e significados a partir de sucessivas elaborações interpretativas e do diálogo com as categorias de "amor líquido" e "amor confluente", aportadas por Bauman ${ }^{7}$ e Giddens ${ }^{5}$.

A pesquisa foi submetida e aprovada por dois Comitês de Ética em Pesquisa.

\section{Resultados e discussão}

Tomando por base a breve reflexão acerca do "amor" e da contemporaneidade apresentada neste artigo, identificamos nos resultados sentidos relacionados ao que categorizamos como: "regras do contrato amoroso" (bloco 1), "atos de ruptura do contrato amoroso" (bloco 2) e "consequências percebidas" (bloco 3 ).

No bloco 1, na enunciação das "regras do contrato amoroso", não percebemos distinção do conteúdo discursivo dos meninos e das meninas. Os enunciados convergem ao que seriam consideradas "regras da etiqueta amorosa" para um "bom" relacionamento, em que são estabelecidas - ainda que informalmente - normas que não podem ser rompidas, sob pena de confrontar valores considerados essenciais ao relacionamento, não raro levando à ruptura do vínculo criado.

Os enunciados evocam sentidos que se fundamentam no reconhecimento de confiança, individualidade e intimidade como essenciais para a vigência de um relacionamento íntimo considerado "sério". Tais valores foram identificados a partir de duas categorias centrais: 1) diálogo/ comunicação e 2) privacidade (Quadro 1).

Ilustradas no Quadro 1, as categorias “diálogo/comunicação" e "privacidade”, associadas aos valores confiança e individualidade, são fortemente evocadas entre os jovens participantes do estudo. Para eles, tais valores são vistos como algo importante à relação. “[...] existem situações pessoais que não cabem serem discutidas com o parceiro” (EPuMa (GF1)). “[...] pode estar resolvendo uma questão de família, pessoal, que não diz respeito à namorada" (EPuMa (GF3)). 
Quadro 1. Distribuição das "regras do contrato amoroso" por categorias, ideias associadas (IA) e valores

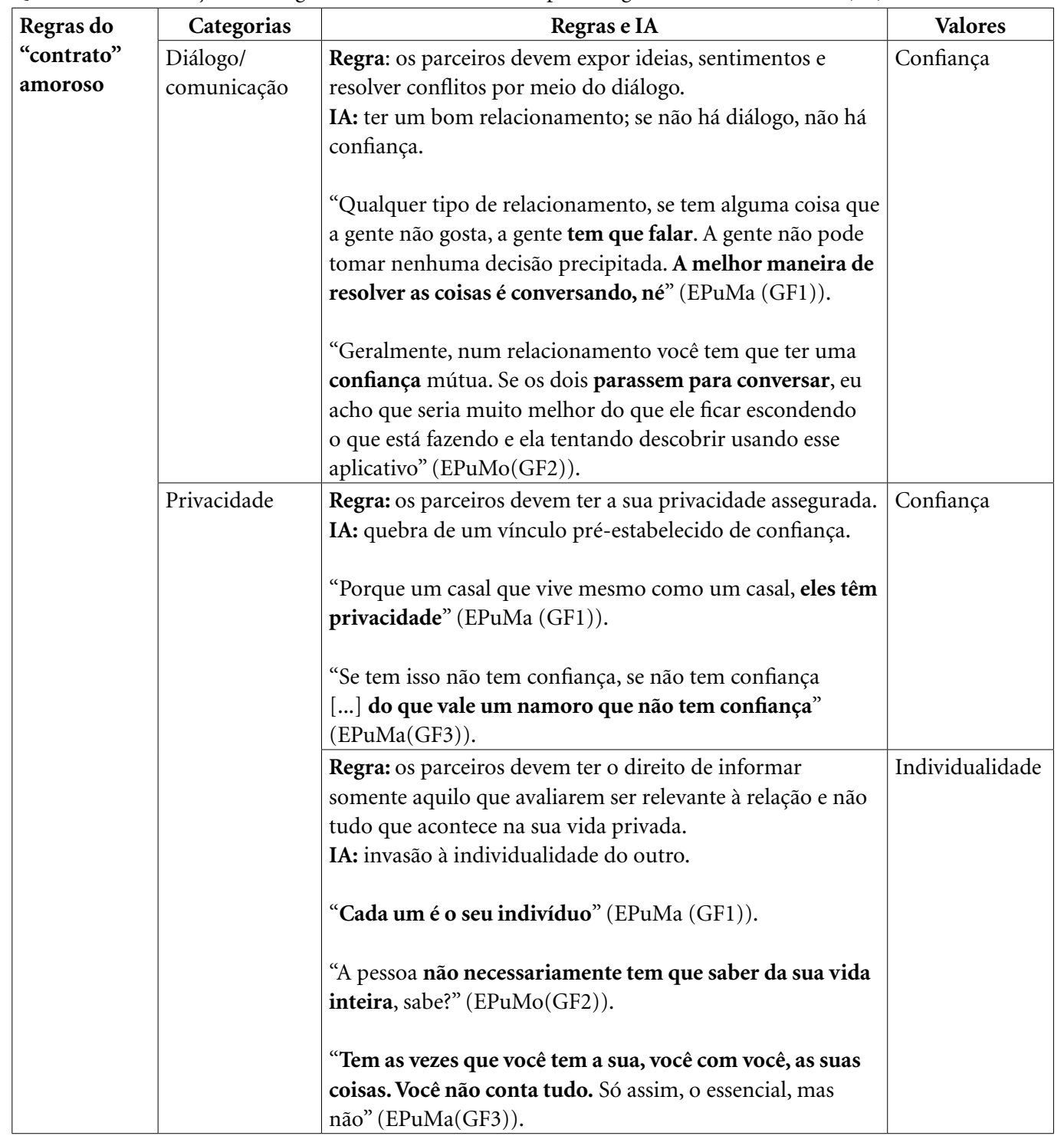

Fonte: Elaborado pelos autores.

O valor "confiança” é evocado pelos jovens especialmente no trato de questões conflitantes, sendo o diálogo o meio idealizado por eles como forma de lidar com dúvidas e discordâncias. Somado à confiança, o valor "individualidade" é conclamado pelos jovens como essencial à garantia de privacidade na relação. Para os jovens entrevistados, apesar de o relacionamento ganhar um status de "compromisso sério", nem tudo deve ser compartilhado com o parceiro, tendo que ser respeitado o espaço individual de ambos no contexto relacional.

Todavia, como somos cotidianamente convidados a nos expor nas mídias e redes sociais, não raro compartilhamos fatos da vida privada e cotidiana como se fossem públicos ${ }^{33-35}$, conflitando diretamente com o desejo de "preservação de individualidade" tão conclamado pelos jovens deste estudo.

$\mathrm{Na}$ atual era da conectividade ${ }^{35}$, "exige-se" de todos a vivência de relacionamentos íntimos fluidos, de laços fracos, baseados na experimentação, na quantidade, no prazer hedonista e imediato, sem estabelecimento de vínculos para não se perder nenhuma potencial possibilidade de algo melhor, o chamado "amor líquido"7. Esses novos tipos e expressões de relacionamentos íntimos (amor confluente e amor líquido ${ }^{7}$ ) convivem 
com velhas práticas de relacionamento (amor romântico), borrando as fronteiras do público e do privado $^{33-35}$.

Assim, ao mesmo tempo em que os jovens buscam sustentar um relacionamento baseado no amor confluente, que, diferentemente do amor líquido e do amor romântico - centrado na figura feminina, na pessoa idealizada, na alma gêmea -, é autocentrado. Isto é, apesar de a relação se manter enquanto existir prazer, o amor confluente admite vínculo e compromisso na relação íntima estabelecida.

Já no bloco 2, "atos de ruptura do contrato amoroso", os enunciados convergem para a crítica a atos que envolvem os sentidos de desrespeito e posse/cerceamento. Por meio das categorias "exposição da intimidade" e "monitoramento sem permissão", os sentidos atribuídos evocavam as condutas a serem repudiadas e que contribuiriam para a ruptura desse "contrato amoroso" (Quadro 2).

Os malefícios advindos dessa "autonomia roubada” ecoando nas falas e os sentimentos de decepção, tristeza, impotência e violação do(a) (ex)parceiro(a) ao não respeitar as regras do "bom relacionamento" são enfaticamente verbalizados pelos participantes.

Houve um consenso nas opiniões tanto dos meninos quanto das meninas, que entendem a exposição de vídeos e fotos de natureza íntima sem consentimento como algo que viola a privacidade e "expõe a intimidade" do parceiro.

A divulgação na Internet de fotos, vídeos íntimos e nudes é relatada pelos jovens como algo que ocorre com muita frequência para ambos os sexos. Apesar disso, quando a divulgação da foto íntima é de um jovem, esta publicização ainda ganha status de "propaganda positiva", o que não ocorre para as jovens, que experienciam o reforço de velhas práticas culturais patriarcais que denigrem a imagem feminina e põem em cheque sua conduta moral (EPuMa (GF1)). Tais atitudes reforçam velhos símbolos da "mulher respeitável" assentados no exercício da sexualidade feminina confinada ao casamento ${ }^{5}$. Aquelas que fugissem a esse modelo seriam taxadas de "mulheres de conduta duvidosa" ${ }^{36-39}$. Enraizado no cotidiano das relações sociais, tais ideários permanecem em constante disputa com outros mais emancipatórios, de igualdade sexual e de gênero.

A diferenciação dos "papeis tradicionais" de gênero naturalizam práticas de abuso e violência, gerando consequências diferentes para rapazes e moças. Aquelas que tentam romper com estes estereótipos tradicionais são estigmatizadas e julgadas, não ocorrendo o mesmo com os rapazes.
“Tipo assim, no meu caso [...] eu estava só conversando com um outro menino [...] alguém, não sei quem é, veio falar pra ele que eu estava conversando com um outro menino [...] enfim, por causa disso ele foi lá e clonou o meu WhatsApp" (EPuMa (GF1)).

“[...] acho que não é só uma questão de exposição, é todo um problema social que você tem sobre o corpo da mulher. Quando eu falo isso, eu falo especificamente da mulher, porque eu notei que o homem não passa por isso, pela mesma situação" (EPuMa (GF3)).

"Aí você para e pensa, cara pra um menino, ele mesmo publicar [...] ele fala pra fulano, dei mesmo e tal, olha só como é grande, é bonito... tipo é [...] a questão social mesmo [...]" (EPuMa (GF3)).

"[...] quando era menino, nude sabe?! Ninguém liga muito, mas quando era menina, sabe?! A menina é taxada, tipo, puta, vadia, de piranha, esse monte de coisa" (EPaMa (GF4)).

Em meio a este turbilhão de oportunidades de relacionamentos, vemos o reforço de comportamentos e julgamentos morais divergentes quando se trata da expressão das sexualidades feminina e masculina. Enquanto aos rapazes é "aceito" que vivenciem o amor confluente e o amor líquido no seu cotidiano relacional, às meninas é "esperado" um comportamento recatado, submisso e introspectivo, baseado no ideal de amor romântico.

Vale ressaltar que a sexualidade é historicamente produzida a partir de múltiplos discursos sobre sexo que não só regulam, normatizam e instauram saberes como produzem "verdades". A mulher aprende desde muito jovem que as questões relativas à sua sexualidade são de ordem privada, desassociando-a de suas raízes sociais e políticas de cerceamento, controle, censura e intimidação ${ }^{6}$.

As jovens são socialmente "educadas" a agir dentro de determinados padrões "moralmente aceitáveis", que incluem: o disciplinamento e controle de seus desejos sexuais, "se darem o respeito", cuidar da forma "como se sentam" e "se vestem" para "não chamar a atenção masculina". Ao mesmo tempo em que também são educadas a se vestirem para o "homem", ficando "bonita" e "atraente ao olhar masculino", para ser "feminina" ${ }^{36-39}$.

Contudo, quando essa mulher "chama atenção do público masculino" e um ato abusivo sexual ocorre com a mesma, são culpabilizadas pelo assédio ou violência sofrida. Serão ainda questionadas quanto "ao horário em que estavam 
Quadro 2. Distribuição dos “atos de ruptura do 'contrato' amoroso” por categorias, ideias associadas (IA) e valores.

\begin{tabular}{|c|c|c|c|}
\hline \multirow{3}{*}{$\begin{array}{l}\text { Atos de } \\
\text { ruptura do } \\
\text { "contrato" } \\
\text { amoroso }\end{array}$} & Categorias & Atos e IA & Valores \\
\hline & $\begin{array}{l}\text { Exposição da } \\
\text { intimidade }\end{array}$ & $\begin{array}{l}\text { Atos de ruptura: quebrar o vínculo de confiança; quando um } \\
\text { dos parceiros disponibiliza na internet material de natureza } \\
\text { íntima produzida enquanto mantinham o relacionamento. } \\
\text { IA: dano à intimidade, um desrespeito a sua privacidade e } \\
\text { integridade. } \\
\text { "Uma amiga da minha prima teve o vídeo dela com o } \\
\text { namorado divulgado. Ela terminou e o namorado resolveu } \\
\text { botar...” (EPuMa (GF1)). } \\
\text { “[...] eu acho muito errado, porque é uma coisa íntima, é o } \\
\text { corpo dela” (EPuMo(GF2)). } \\
\text { "Porque tipo assim, uma coisa que você faz a dois, você e sua } \\
\text { namorada, não se compartilha a quatro” (EPuMo(GF2)). } \\
\text { "No momento que você pega a nossa coisa e espalha } \\
\text { [...] o ato de você publicar, expor para as pessoas que não } \\
\text { tinham o consentimento de ver, isso sim é que está errado” } \\
\text { (EPuMa(GF3)). } \\
\text { “A partir do momento que as pessoas compartilham, você } \\
\text { perde o controle. Como é o seu corpo, é você que é afetada, } \\
\text { não a pessoa que está compartilhando" (EPaMa(GF4)). } \\
\text { “[...] mesmo quando você tem uma relação boa com o seu } \\
\text { corpo, você super se aceita, você tem ainda a questão da sua } \\
\text { privacidade e a questão de você escolher, essa pessoa eu } \\
\text { quero, essa pessoa eu não quero, sabe!?!” (EPaMa(GF4)). }\end{array}$ & Desrespeito \\
\hline & $\begin{array}{l}\text { Monitoramento } \\
\text { sem permissão }\end{array}$ & $\begin{array}{l}\text { Atos de ruptura: monitorar sem a permissão do(a) parceiro(a) } \\
\text { IA: é entendido como um abuso, um controle obsessivo, um } \\
\text { ato de possessão que por meio da vigilância expõe e invade a } \\
\text { privacidade dos parceiros. } \\
\text { "Mas eu acho que a gente não pode confundir também, uma } \\
\text { coisa é você ter ciúmes do seu namorado, isso é provavelmente } \\
\text { normal, outra coisa é você [...] baixar num celular [...] é você } \\
\text { ter, entre aspas, abusar da pessoa, você ser invasivo e tal" } \\
\text { (EPuMa (GF1)). } \\
\text { "Uma amiga [...] teve um dia que ela me falou que descobriu } \\
\text { que o namorado dela tinha colocado esse aplicativo de } \\
\text { mensagem no celular dela [...] o namorado dela sempre foi } \\
\text { muito possessivo com ela [...] então eles terminaram [...]" } \\
\text { (EPuMo(GF2)). } \\
\text { “[...] um ato de possessão colocar o aplicativo pra ver o que } \\
\text { ele estava fazendo com as mensagens e tal” (EPuMo(GF2)). } \\
\text { "É um controle obsessivo, isso é obsessão" (EPuMa(GF3)). } \\
\text { "Porque o aplicativo já está errado por existir. Onde já se viu } \\
\text { um aplicativo pra botar no celular da outra pessoa pra saber } \\
\text { tudo" (EPuMa(GF3)). } \\
\text { "Que é uma parada dela, não é sua. Você não tem o direito de } \\
\text { mexer no celular de outra pessoa" (EPaMa(GF4)). }\end{array}$ & $\begin{array}{l}\text { Posse/ } \\
\text { cerceamento }\end{array}$ \\
\hline
\end{tabular}


transitando sozinhas", ao "tipo de roupa que vestiam" e "se tinham ingerido bebida alcóolica"40,41.

E é justamente por conta da forma como o corpo da mulher é visto e de como ela é julgada social e moralmente que encontramos alguns discursos das meninas enfatizando o quanto é difícil confiar em uma outra pessoa, a ponto de expor a sua sexualidade de forma plena, sem receio de julgamentos, retaliações ou de que situações de abuso ocorram, como quando o "sexting" vira "sextorsão" ou "pornografia de vingança".

A mediação por parte do Estado no que se entende por CDA surge como um apelo vocalizado nas entrevistas ao reordenamento moral daquilo que o senso comunitário não é mais capaz de coibir por si só. Assim, torna-se compreensível que alguns jovens enfatizem em seu discurso a necessidade da criação de uma lei que pudesse coibir este tipo de comportamento abusivo nos meios digitais, tendo em vista que os mecanismos de controle de comportamentos acionados pelos agentes familiares ou educacionais nem sempre são suficientes. "É, então, ainda essa coisa, a internet parece algo sem lei” (EPuMo (GF2)). "Então, eu acho que devia ter uma medida pra proibir, ou algo assim, uma lei pra acabar com isso" (EPuMo (GF2)).

A judicialização das relações interpessoais tem sido uma prática recorrente para mediar de conflitos pessoais e íntimos ${ }^{42,43}$. Cabe ressaltar que no momento da realização dos grupos focais, entre os meses de abril e agosto de 2018, estavam tramitando no Congresso Nacional brasileiro diversos projetos de lei com o propósito de coibir a prática do abuso digital nos relacionamentos afetivo-sexuais, porém ainda sem aprovação. Mas no mês de setembro daquele ano, entrou em vigência a Lei 13.718/18, que tipifica o crime conhecido como vingança pornográfica. Por ser recente, ainda não há fontes de registros estatísticos oficiais que informem se a mesma já promoveu alguma redução desse tipo de prática na internet.

No bloco 3, "consequências percebidas" (Quadro 3), por meio das categorias "danos à saúde mental/física" e "danos à inserção social/ socialização", é possível refletir sobre a importância que os adolescentes conferem às consequências do abuso digital nos relacionamentos íntimos juvenis.

Os danos à saúde relacionados às práticas de CDA foram espontaneamente informados pelos jovens durante os grupos focais. Esses dados demarcam a importância de se ter um olhar atento para esse fenômeno emergente e cujas consequências ainda são de difícil mensuração.
$\mathrm{O}$ abuso digital nos relacionamentos íntimos juvenis demonstra o quanto se faz necessário um trabalho multidisciplinar e interinstitucional visando ampliar as possibilidades de acesso ao apoio e à identificação do abuso digital nos relacionamentos afetivos-sexuais juvenis pelas equipes de saúde, ensino e demais instituições da sociedade civil.

Os depoimentos apresentados no Quadro 3 ratificam que sem apoio profissional adequado se torna muito penoso para o jovem superar o abuso sofrido, sendo cotidianamente revitimizado, seja na escola, por meio das redes sociais digitais, $e$-mails ou demais mensagens eletrônicas. Esse ciclo quase que infindável de sofrimento pode, e na maioria das vezes de fato é, um fator determinante no desenvolvimento de consequências para a saúde mental e física e para o próprio processo de socialização juvenil.

Comonos mostra a literatura internacional, não raro esses jovens expostos a tal abuso no relacionamento afetivo-sexual desenvolvem quadros de baixa autoestima, isolamento, depressão, crise de pânico e ansiedade, podendo levar à automutilação e até mesmo à tentativa de suicídio ${ }^{14,15,19,22,23}$.

\section{Considerações finais}

Identificamos que, concomitantes ao desejo de privacidade e individualidade, alinhavam-se demandas de exposição e liberdade, próprias da "cultura da conectividade" 35 . Parece contraditório que desejos antagônicos sejam tão fortemente conclamados por esses jovens, mas acreditamos que tais manifestações têm íntima relação com os modelos amorosos em voga e sua expressão nas mídias digitais. Expor fatos e eventos relativos à vida privada é algo naturalizado e faz parte do cotidiano digital. Apesar disso, algumas atitudes "ferem" aquilo que os adolescentes entendem por uma "autonomia do indivíduo" para decidir o que deve ser publicizado, quando e, principalmente, para quem.

A questão da decisão de "para quem eu envio" um conteúdo de natureza íntima, ou seja, para qual audiência decido expor a minha intimidade, foi um dado importante e fortemente declarado pelos jovens no momento da pesquisa. Trata-se da prerrogativa de escolha da mídia e da audiência a se expor. Novas regras morais, desenhadas na interface com a sociabilidade digital, que aportam questões originais e exigem um novo olhar dos profissionais de saúde e educação que trabalham com esses segmentos. 
Quadro 3. Distribuição das "consequências percebidas” por categorias e sentidos atribuídos

\begin{tabular}{|c|c|c|}
\hline \multirow{3}{*}{$\begin{array}{l}\text { Consequências } \\
\text { percebidas }\end{array}$} & Categorias & Sentidos atribuídos \\
\hline & $\begin{array}{l}\text { Danos à saúde } \\
\text { mental/física }\end{array}$ & $\begin{array}{l}\text { A pessoa que vivencia o abuso online no relacionamento íntimo entra em } \\
\text { um sofrimento profundo, podendo sofrer "depressão", "paranoia”, práticas } \\
\text { de automutilação e ideação suicida } \\
\text { "Então a pessoa fica extremamente deprimida, a ponto de chegar à } \\
\text { depressão, com certeza, porque isso, com certeza é... se mantem por muito } \\
\text { tempo" (EPuMo(GF2)). } \\
\text { "Eu acho que a pessoa fica realmente em estado mental que chega... é... } \\
\text { depressão, paranoia" (EPuMo(GF2)). } \\
\text { "A garota entrou em depressão com isso. É um sentimento que... tipo } \\
\text { assim, pior que for" (EPuMo(GF2)). } \\
\text { "Tipo, ela entrou numa depressão muito grave" (EPuMa(GF3)). } \\
\text { "Uma coisa que é tão íntima vir a público. A garota queria se matar, porque } \\
\text { todo mundo falando, vendo. É horrível” (EPuMo(GF2)). } \\
\text { "Eu conheço um caso, este é pesado, porque a menina depois que isso } \\
\text { aconteceu ela começou a se mutilar..." (EPuMa(GF3)). }\end{array}$ \\
\hline & $\begin{array}{l}\text { Inserção social/ } \\
\text { socialização }\end{array}$ & $\begin{array}{l}\text { O dano gerado pode contribuir para a reclusão, afetando diretamente o } \\
\text { processo de inserção social. } \\
\text { "Uma amiga da minha prima teve o vídeo dela com o namorado divulgado. } \\
\text { Ela terminou o namoro e o namorado resolveu botar [...] ela se mudou de } \\
\text { escola [...] ela ficou muito chateada. Ela ficou muito tempo sem sair de } \\
\text { casa" (EPuMa (GF1)). } \\
\text { "E aí todo mundo ficou sabendo, aí ela se sentiu muito humilhada. Como } \\
\text { estava no final do ano, ela esperou completar o ano e saiu da escola. Mas foi } \\
\text { uma situação bem braba, até hoje na escola falam disso..." (EPuMa(GF3)). } \\
\text { "Sendo adolescente, sendo vítima de uma coisa assim é [...] fora o } \\
\text { julgamento social que tem em cima disso, tem o julgamento da família } \\
\text { também, porque pode ter uma resposta tipo, mudar a relação com você, te } \\
\text { decepcionar" (EPuMa(GF3)). } \\
\text { "Pode ter gente do outro lado do mundo vendo... me vendo pelada. Aí eu } \\
\text { acho que isso, sei lá, eu acho que a minha vontade seria de ir embora. Acho } \\
\text { que nunca mais ver ninguém [...] com certeza eu ia pedir pra minha mãe } \\
\text { me tirar da escola [...] mudar de estado, mudar de país" (EPaMa(GF4)). }\end{array}$ \\
\hline
\end{tabular}

Fonte: Elaborado pelos autores.

Observamos neste estudo que os jovens têm expectativas e balizam relacionamentos pela ideia de um amor confluente ${ }^{5}$, mas inseridos num cenário social em que se desenvolve, com intensidade, o amor líquido ${ }^{7}$, e não raro com recorte de gênero, é imposto às meninas os ditames do amor romântico. Esses modelos distintos de amor convivem e disputam os sentidos dos limi- tes e a demarcação de fronteiras de um "contrato amoroso". Consideramos que uma das limitações do nosso estudo foi ter incluído poucos meninos. Tampouco a questão da orientação sexual foi tratada. As diferenças sociais de renda nas experiências de abuso digital não foram captadas nos depoimentos, seja pelo uso disseminado das tecnologias, independentemente da renda, seja 
pelo universo reduzido de escolas. Nosso campo se limitou ao contexto urbano, não captando os sentidos de outras territorialidades.

Outro dado relevante identificado foi o fato de esses jovens tentarem proteger os mais jovens que eles no uso da Internet. Isso pode ter relação com o entendimento, ainda que precoce, das consequências que uma exposição nas redes pode acarretar à vida de quem sofre tal abuso. As "consequências" apontadas pelos entrevistados parecem evidenciar que os danos à saúde mental e à inserção social daqueles que vivenciam tais abusos digitais são reconhecidas a partir das experiências desses jovens. Portanto, levar em consideração essas práticas abusivas e (des)natu- ralizá-las são movimentos essenciais e urgentes a serem providos nos diversos espaços de reprodução social, como: família, comunidade, escolas e unidades de saúde. No entanto, como o percurso da pesquisa nos mostrou, faz pouco sentido discutir isoladamente o abuso digital entre parceiros afetivo-sexuais e suas formas de prevenção e enfrentamento. Estratégias que tratem apenas normativamente de "como se proteger de abusos digitais" não parecem dar conta da complexidade do tema. Os adolescentes nos mostraram que é preciso tratar a questão a partir da reflexão sobre as regras, os valores e os acordos - implícitos ou pactuados - que definem os contornos do "contrato amoroso" que estabelecem.

\section{Colaboradores}

RMD Flach e SF Deslandes trabalharam igualmente na elaboração do artigo.

\section{Referências}

1. Flach R, Deslandes SF. Abuso digital nos relacionamentos afetivo-sexuais: uma análise bibliográfica. Cad Saude Publica 2017; 33(7):e 00138516.

2. Flach R, Deslandes SF. Abuso digital ou prova de amor? O uso de aplicativos de controle/monitoramento nos relacionamentos afetivo-sexuais. Cad Saude Publica 2019; 35(1):e00060118.

3. Bertoldo RB, Barbara A. Representação social do namoro: a intimidade na visão dos jovens. Psico-USF 2006; 11(2):229-237.

4. Scorsolini-Comin F, Fontaine AMGV, Santos MA. Satisfação no namoro e bem-estar subjetivo: associações com conjugalidade dos pais. Psic: Teor e Pesq 2016; 32(3):1-8.

5. Giddens A. A transformação da intimidade: Sexualidade, amor e erotismo nas sociedades modernas. São Paulo: Editora UNESP; 1993.

6. Louro GL. Pedagogia da sexualidade. In: Louro GL, organizadora. O corpo educado: pedagogias da sexualidade. Belo Horizonte: Autêntica; 2000.

7. Bauman Z. Amor líquido: Sobre a fragilidade dos laços humanos. Rio de Janeiro: Zahar; 2004.

8. Chaves JC. As percepções de jovens sobre os relacionamentos amorosos na atualidade. Psicologia em Revista 2010; 16(1):28-46.

9. Marinho S. Diversidade de gênero na sociabilidade capitalista patriarcal: as identidades trans em perspectiva. Rev katálysis 2018; 21(3):602-610.

10. Santaella L. Intersubjetividade nas redes digitais: repercussões na educação. In: Primo A, organizador. Interações em rede. Porto Alegre: Sulina; 2016.

11. Justo JS. O "ficar" na adolescência e paradigmas de relacionamento amoroso da contemporaneidade. Revista do Departamento de Psicologia - UFF 2005; 17(1):61-77. 
12. Nascimento FS, Cordeiro RLM. Violência no namoro para jovens moradores de Recife. Psicol Soc 2011; 23(3):516-525.

13. Van Ouytsel J, Ponnet K, Walrave M. Cyber dating abuse victimization among secondary school students from a lifestyle-routine activities theory perspective. $J$ Interpers Violence 2016; 33(17):1-10.

14. Borrajo E, Gaméz-Guadix M, Calvete E. Justification beliefs of violence, myths about love and cyber dating abuse. Psicothema 2015; 27(4):327-333.

15. Stonard KE, Bowen E, Lawrence TR, Price AS. The relevance of technology to the nature, prevalence and impact of adolescent dating violence and abuse: a research synthesis. Aggress Violence Behav 2014; 19:390417.

16. Morelli M, Bianchi D, Baiocco R, Pezzuti L, Chiumbolo A. Sexting, psychological distress and dating violence among adolescents and young adults. Psicothema 2016; 28(2):137-142.

17. Lucero JL, Weisz AN, Smith-Darden J, Lucero SM. Exploring gender differences: socially interactive technology use/abuse among dating teens. Affilia 2014; 29:478-491.

18. SaferNetBrasil. Institucional/SaferNet; 2019. [acessado 2019 Jul 20]. Disponível em: http://new.safernet.org. br

19. Temple JR, Choi HJ, Brem M, Wolford-Clevenger C, Stuart GL, Peskin MF, Elmquist J. The temporal association between traditional and cyber dating abuse among adolescents. J Youth Adolesc 2016; 45(2):340349.

20. Martinez C. An argument for States to outlaw 'revenge porn' and for Congress to Amend 47 U.S.C 230: how our current laws do little to protect victims. Journal of Technology Law \& Police 2014; 14:236-52.

21. Tungate A. Bare necessities: the argument for a 'revenge porn' exception in Section 230 immunity. Information \& Communications Technology Law 2014; 23:172-188.

22. Zweig JM, Lachman P, Yahner J, Dank M. Correlates of cyber dating abuse among teens. J Youth Adolesc 2014; 43(8):1306-1321.

23. Dank M, Lachman P, Zweig JM, Yahner J. Dating violence experiences of lesbian, gay, bissexual, and transgender youth. J Youth Adolesc 2014; 43(5):846-857.

24. Convenção Interamericana para prevenir, punir e erradicar a violência contra a mulher. Convenção de Belém do Pará; 1994.

25. Miller E, Goldstein S, McCauley HL, Jones KA, Dick RN, Jetton J, Silverman JG, Blackburn S, Monasterio E, James L, Tancredi DJ. A school health center intervention for abusive adolescent relationships: a cluster RCT. Pediatrics 2015; 135(1):76-85.

26. Niolon PH, Vivolo-Kantor AM, Latzman NE, Valle AL, Kuoh H, Burton T, Taylor BG, Tharp AT. Prevalence of teen dating violence and co-occurring risk factors among middle school youth in high-risk urban communities. J Adolesc Health 2015; 56(suppl. 2):s5-s13.

27. Minayo MCS, Assis SG, Njaine K, organizadores. Amor e violência: um paradoxo das relações de namoro e do "ficar" entre jovens brasileiros. Rio de Janeiro: Editora Fiocruz; 2011.
28. Coelho C, Machado C. Violência entre jovens: prevenção através da educação por pares. Actas do VI Simpósio Nacional de Investigação em Psicologia. Universidade de Minho, Portugal, 4 a 6 de fevereiro de 2010.

29. Caridade $S$, Machado C. Violência na intimidade juvenil: da vitimização à perpetração. Análise Psicológica 2006; 24(4):485-493.

30. Pinto ER. Conceitos fundamentais dos métodos projetivos. Agora (Rio de Janeiro) 2010; 17(1):135-153.

31. Minayo MCS. O desafio do conhecimento: pesquisa qualitativa em saúde. São Paulo: Hucitec; 2010.

32. Gomes R, Souza ER, Minayo MCS, Malaquias JV, Silva CFR. Organização, processamento, análise e interpretação de dados: o desafio da triangulação. In: Minayo MCS, organizadora. Avaliação por triangulação de métodos: abordagem de programas sociais. Rio de Janeiro: Editora Fiocruz; 2005, p.185-221.

33. Bauman Z. Vida líquida. Rio de Janeiro: Zahar; 2009.

34. Bruno F. Máquinas de ver, modos de ser: vigilância, tecnologia e subjetividade. Porto Alegre: Sulina; 2013.

35. Van Dijck J. La cultura de la conectividade: una historia crítica de las redes sociales. Buenos Aires: Siglo Veintiuno Editores; 2016.

36. Laranjeira LQM. Mulheres perigosas: uma análise da construção da categoria piriguete [dissertação]. Rio de Janeiro: Programa de Pós-graduação em Sociologia e Antropologia (IFCS-UFRJ); 2016.

37. Nascimento CG. Piriguetes em cena: uma leitura do corpo feminino a partir dos pagodes baianos. In: Fazendo gênero 9 - Diásporas, diversidade e deslocamentos. Florianópolis: UFSC; agosto 2010.

38. Cerqueira LC, Corrêa LG, Rosa MG. A cartilha da mulher adequada: ser piriguete e ser feminina no Esquadrão da Moda. Revista Contracampo 2012; 1(24):120.

39. Misse M. O estigma do passivo sexual: um símbolo de estigma no discurso cotidiano. Rio de Janeiro: Booklink/NECVU; 2007.

40. Peixoto AF, Nobre BPR. A responsabilização da mulher vítima de estupro. Revista Transgressões - Ciências Criminais em Debate 2015; 3(1): 227-239.

41. IPEA. Instituto de Pesquisa Econômica e Aplicada (IPEA). Estupro no Brasil: uma radiografia segundo os dados da Saúde (versão preliminar). Brasília: IPEA; 2014.

42. Oliveira CFB, Brito LMT. Humanização da justiça ou judicialização do humano? Psicol Clin 2016; 28(2):149-172.

43. Rifiotis T. Violência, justiça e direitos humanos: reflexões sobre a judicialização das relações sociais no campo da violência de gênero. Cad Pagu 2015; 45:261295.

Artigo apresentado em 19/08/2019

Aprovado em 10/02/2020

Versão final apresentada em 12/02/2020

Editores-chefes: Romeu Gomes, Antônio Augusto Moura da Silva 